\title{
풍속 재현빈도와 일치하는 해일모의용 표준태풍 생성 Generation of a Standard Typhoon using for Surge Simulation Consistent with Wind in Terms of Return Period
}

\author{
강주환* · 김양선* · 권순덕** · 전영선*** \\ Ju Whan Kang*, Yang-Seon Kim*, Soon-Duck Kwon** and Young-Sun Choun***
}

\begin{abstract}
요 지 : 서해안에 영향을 미친 태풍자료를 사용하여 몬테칼로 시뮬레이션을 통해 목포를 비롯하여 군산, 인천 및 제주 등 서해안 4곳의 빈도별 풍속을 산정하였다. 민감도분석 결과 최근접거리와 최대풍속반경의 차이가 풍속에 가 장 영향을 크게 미치는 요소이고 위치각과 기압강하량 역시 민감한 반면 이동속도는 가장 둔감한 매개변수로 나타 나고 있다. 이를 토대로 빈도별 최대풍속을 발생시키는 평균적인 해당빈도의 표준태풍을 설정할 수 있으며, 각 지 점에서의 태풍 매개변수 설정을 통해 표준태풍을 확립할 수 있다. 이러한 표준태풍을 통해 빈도별 풍속과 일맥상 통하는 빈도별 해일고 역시 산정할 수 있게 된다. 또한 가항반원에 해당하는 자료만 포함시켜 해석함으로써 음해 일을 유발하는 표준태풍 역시 생성할 수 있다.

핵심용어 : 표준태풍, 민감도분석, 재현기간, 몬테칼로 시뮬레이션, 서해안
\end{abstract}

\begin{abstract}
Extreme wind speeds at four sites including Mokpo, Gunsan, Incheon and Jeju near the Western Coast have been estimated with a tool of Monte Carlo simulation and typhoon data. Results of sensitivity analysis show that closeness between distance to the eye and the radius to maximum wind is most sensitive. While location angle and pressure deficit are sensitive too, but translation velocity is not. A standard typhoon, which results in extreme wind speeds having various return period, can be constructed by combination of parameter informations of each site. Then, with a numerical modelling of the typhoon, extreme surge heights having the same return period can also be obtained. To be added, by analysing the data which only including those based on navigable semicircle, it is possible to produce a standard typhoon which could result in setting-down of sea level.
\end{abstract}

Keywords : standard typhoon, sensitivity analysis, return period, monte carlo simulation, western coast

\section{1. 서 론}

극치해면고 산정방법의 대표적인 방법으로 확률분포함수를 토대로 하여 매개변수 추정을 통해 빈도별 해면고를 산정하 는 방법이 있다. 그러나 이 방법은 매년 한 개 정도의 고극 조위 자료만 사용하므로 자료의 낭비가 심하고 대규모 해일 이 높지 않은 조위상황에서 발생한 경우 결과에 반영되지 않 을 수 있다는 단점이 있다(Toro et al., 2010). 이러한 단점을 극복하기 위한 방법으로 과거사상을 비모수적 방법으로 해석 하는 EST(empirical simulation technique) 기법(Scheffner et al., 1999)이 최근 널리 사용되고 있다. 여기에 부가하여 조 석이 지배적인 해역에 적용가능한 방법이 제안된 바 있고 (Goring et al., 2011), 국내에서도 개량된 방법이 목포해역에 적용된 바 있다(Kang et al., 2012). 이 방법은 조위조건을
토대로 한 후 태풍 및 비태풍 해일고를 독립적으로 모의하여 이들을 합산함으로써 극치해면고를 산정하는 방법이다. 이때 과거 발생했던 태풍자료를 근간으로 트레이닝세트가 구성되 는데 과거자료의 한계성을 탈피하기 위해 가상태풍을 모의하 여 그 결과를 트레이닝세트에 포함시켜 해석할 수 있다 (Divoky and Resio, 2007). 여기서 가상태풍은 향후 발생할 수 있는 매우 큰 규모의 태풍을 대상으로 한다는 빈도개념이 결여된 다소 막연한 개념으로 설정되고 있다.

해일고와는 달리 최대풍속은 태풍조건으로부터 개략적으로 산출이 가능하며 관측자료도 풍부하다. 따라서 본 연구에서 는 EST기법의 트레이닝세트에 포함되는 가상태풍 또는 설계 태풍의 빈도를 설정하기 위하여 각 태풍에 의해 유발되는 최 대풍속자료를 활용하고자 한다. 이를 위해 먼저 태풍에 의해 발생된 빈도별 최대풍속을 산정한 후 해당 최대풍속을 유발

*목포대학교 토목공학과 (Corresponding author: Ju Whan Kang, Dept. of Civil Engineering, Mokpo National University, Muan-gun, Jeonnam 534-729, Korea, Tel:+82-61-450-2473, Fax:+82-61-452-6468, jwkang@mokpo.ac.kr)

**전북대학교 토목공학과 (Dept. of Civil Engineering, Chonbuk National University) ***한국원자력연구원 (Korea Atomic Energy Research Institute) 
한 태풍환경을 역추적하여 일명 ‘표준태풍'을 생성하기 위한 매개변수를 추출한다. 즉, 빈도별 풍속과 일맥상통하는 빈도 별 해일고를 발생시키는 대표적인 빈도별 태풍인 표준태풍의 매개변수를 해당지역에서 생성한다. 태풍 진행방향에 따라 몇 개 지점에서 이러한 태풍 매개변수를 설정함으로써 표준태풍 의 경로와 기압강하량 등을 비롯한 제반 태풍정보를 확정하 여 궁극적인 표준태풍을 확립할 수 있다. 이렇게 함으로써 EST 기법에 포함되는 가상태풍에 빈도를 설정할 수 있을 뿐 아니라 조석이 지배적이지 않은 동해안과 같은 해역에서는 표 준태풍 자체를 설계태풍으로 취하여 해당 빈도의 해일 모의 도 가능하게 된다.

태풍에 의해 계측된 풍속은 이벤트 성질을 띠기 때문에 연 최고풍속을 이용한 극치해석은 시행하지 않고 몬테칼로(Monte Carlo) 시뮬레이션과 같은 간접적인 방법을 통해 추정하는 것 이 일반적이라고 알려져 있다(Lee et al., 2007). 태풍의 몬테 칼로 시뮬레이션 방법은 Russell(1971)이 멕시코만에서 발생 한 허리케인이 텍사스 연안의 해양석유시설에 미치는 영향을 파악하기 위해 처음 개발되었다. 본 연구에서도 몬테칼로 시 뮬레이션을 통해 빈도별 최대풍속을 산정하고자 하는데, 국외 연구사례(Batts et al., 1980; Vickery and Twisdale, 1995) 뿐 아니라 국내에서도 연구사례(Kim et al., 2005; Lee et al., 2007; Kwon and Lee, 2008)는 풍부한 편이다.

\section{2. 자료분석}

일본 기상청에서 운영하는 RSMC(Regional Specialized Meteorological Center)-Tokyo에서는 1951년 이후의 태풍정 보를 최적경로자료 형태로 제공하고 있다. 본 연구에서는 이 자료 중 자료의 신뢰도 및 동질성을 감안하여 1978년 이후 자료에 대해서만 한반도에 영향을 미친 태풍 중 TY급 및 STS급 태풍을 해석대상으로 선정하였다. 인천, 군산, 목포 등 서해안 지역과 제주의 표준태풍을 설정하기 위해 해당 4 개 지 역 외에 이어도 지점을 추가로 분석하였다.

한편 몬테칼로 시뮬레이션에서 최적영향반경 설정에 관한 연 구결과(Cho and Kim, 2009)에 따르면 해당 지점에서 임의의 반경을 설정한 후 여기를 통과하는 태풍을 선정하게 되는데 반경의 크기는 최소 $150 \mathrm{~km}$ 이어야 하며 $300 ~ 500 \mathrm{~km}$ 가 적절 하다는 결론을 제시한 바 있다. 반경이 커질수록 다양한 태풍 을 포함할 수 있다는 장점이 있는 반면 현실적으로 발생하기 어려운 태풍까지 포함하게 된다는 단점이 함께 내재되어 있 다. 목포지역을 예로 들면 목포를 중심으로 $500 \mathrm{~km}$ 이내를 지 나는 태풍 중 기압강하량이 가장 큰 태풍은 MIREILLE(9119) 로서 $367.7 \mathrm{~km}$ 떨어진 최근접거리를 지날 때 $940.5 \mathrm{hPa}$ 을 기 록하고 있으며 이는 목포지역에서 발생하기는 다소 비현실적 인 수치이다. 따라서 본 연구에서는 이러한 비현실적인 태풍 이 배제되도록 반경 $300 \mathrm{~km}$ 이내 태풍 51 개를 대상으로 하 였다. 이렇게 선정된 태풍 경로를 Fig. 1에 제시하였는데 각

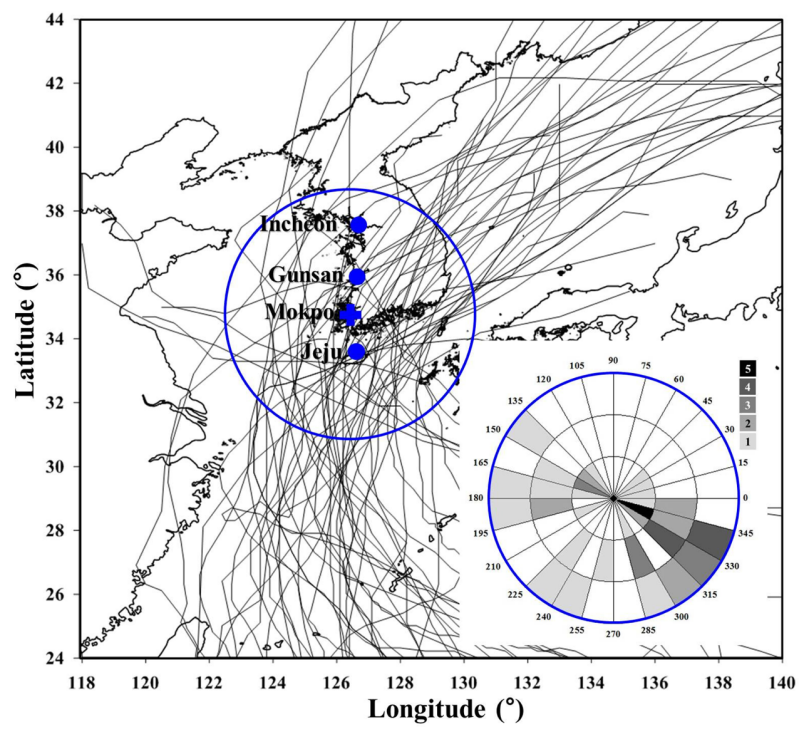

Fig. 1. Typhoon tracks and corresponding circle diagram which depicts their angles when the typhoon is on the nearest position at Mokpo.

태풍별로 경로상에서 목포에 최근접한 위치를 기준으로 $100 \mathrm{~km}$ 거리별, 15 도 방향별 태풍수를 그림의 우하단에 함 께 나타내었다. 대상 태풍 중 최근접거리가 정북쪽에서 형성 된 경우는 전무하였고 가항반원인 동쪽을 통과한 태풍이 32 개로 위험반원인 서쪽을 통과한 태풍수 19 개보다 배 가까이 많은 것으로 나타나고 있다.

각 태풍의 해당지점 최근접시 태풍의 위경도, 중심기압, 최 근접거리, Coriolis, 이동속도, 위치각 등의 매개변수는 RSMC 자료를 이용하여 산정하였으며 목포지점에 대한 예를 Table 1 에 제시하였다. 즉, 태풍의 위도와 경도는 목포 조위관측소 와의 최근접시 좌표이며 이때 태풍의 중심과 해당지점과의 거 리를 측정하여 최근접거리로 산정하였다. 중심기압 및 이동 속도는 3 6시간 간격으로 발표되는 정보를 토대로 최근접거 리에 위치하였을 때의 값을 내삽법으로 산정하였다. 또한 위 치각은 최근접시 위치를 Fig. 1에 나타내었듯이 정동쪽을 0 도로 하고 반시계방향의 각도로 설정하였다.

\section{3. 몬테칼로 시뮬레이션}

\section{1 최대풍속 산정}

태풍시 발생하는 풍속의 빈도를 산정하기 위해 몬테칼로 시 뮬레이션을 적용하였다. 여기에는 임의로 발생되는 태풍 매 개변수에 따라 풍속이 산정되는 과정이 포함되어 있는데, 최 대풍속 산정을 위해 태풍의 바람장 모델인 Holland(1980) 모 델을 이용하였다. 태풍의 눈에서 $r$ 만큼 떨어진 곳의 1 분 평 균 경고도 풍속은 다음 식 (1)과 같이 표현된다.

$$
V_{g, 1}(r)=\frac{V_{T} \sin \theta-f \cdot r}{2}+\sqrt{\left(\frac{V_{T} \sin \theta-f \cdot r}{2}\right)^{2}+\frac{\Delta P \cdot B}{\rho}\left(\frac{r_{0}}{r}\right)^{B} e^{-\left(\frac{r_{0}}{r}\right)^{B}}}
$$


Table 1. Parameters of the selected typhoons on the nearest position at Mokpo

\begin{tabular}{|c|c|c|c|c|c|c|c|}
\hline Typhoon No. & $\begin{array}{l}\text { Lat. } \\
\left({ }^{\circ}\right)\end{array}$ & $\begin{array}{l}\text { Lon. } \\
\left({ }^{\circ}\right)\end{array}$ & $\begin{array}{c}\text { Pressure } \\
(\mathrm{hPa})\end{array}$ & $\begin{array}{c}\text { Distance } \\
(\mathrm{km})\end{array}$ & Coriolis & $\begin{array}{c}\text { Trans. Vel. } \\
(\mathrm{m} / \mathrm{s})\end{array}$ & $\begin{array}{c}\text { Angle } \\
\left({ }^{\circ}\right)\end{array}$ \\
\hline 7811 & 34.5 & 126.7 & 987.6 & 39.1 & 0.000082 & 10.8 & 323 \\
\hline 7818 & 32.6 & 127.6 & 970.0 & 267.5 & 0.000078 & 7.7 & 302 \\
\hline 7910 & 35.0 & 126.1 & 968.3 & 38.7 & 0.000084 & 9.5 & 143 \\
\hline 7911 & 33.5 & 127.0 & 990.0 & 150.4 & 0.000080 & 7.0 & 300 \\
\hline 8105 & 32.4 & 127.4 & 990.4 & 274.9 & 0.000078 & 14.0 & 296 \\
\hline 8118 & 33.6 & 126.9 & 979.2 & 139.5 & 0.000081 & 8.8 & 297 \\
\hline 8410 & 33.2 & 127.7 & 970.0 & 203.8 & 0.000080 & 7.3 & 314 \\
\hline 8508 & 34.6 & 126.6 & 991.5 & 26.8 & 0.000083 & 7.3 & 335 \\
\hline 8509 & 35.4 & 124.4 & 982.5 & 193.9 & 0.000084 & 11.2 & 162 \\
\hline 8520 & 33.6 & 127.6 & 988.9 & 169.0 & 0.000081 & 12.1 & 319 \\
\hline 8605 & 33.8 & 127.3 & 996.3 & 130.5 & 0.000081 & 18.4 & 319 \\
\hline 8613 & 35.1 & 125.7 & 963.0 & 74.8 & 0.000084 & 10.5 & 157 \\
\hline 8705 & 34.4 & 127.2 & 970.9 & 87.2 & 0.000082 & 13.2 & 339 \\
\hline 8712 & 33.5 & 128.5 & 945.0 & 235.0 & 0.000080 & 14.4 & 333 \\
\hline 8911 & 35.2 & 127.4 & 991.4 & 95.2 & 0.000084 & 10.8 & 24 \\
\hline 9007 & 34.1 & 126.6 & 992.0 & 77.1 & 0.000082 & 6.9 & 291 \\
\hline 9109 & 33.3 & 128.2 & 950.0 & 234.4 & 0.000080 & 7.5 & 324 \\
\hline 9112 & 35.3 & 126.9 & 988.7 & 72.7 & 0.000084 & 8.0 & 38 \\
\hline 9113 & 34.1 & 129.0 & 998.0 & 251.4 & 0.000082 & 4.2 & 342 \\
\hline 9219 & 35.5 & 125.8 & 994.0 & 97.9 & 0.000085 & 17.0 & 130 \\
\hline 9411 & 34.9 & 126.0 & 993.6 & 36.9 & 0.000083 & 9.0 & 165 \\
\hline 9413 & 34.0 & 125.7 & 990.0 & 107.4 & 0.000081 & 1.3 & 232 \\
\hline 9429 & 34.2 & 127.0 & 980.0 & 78.9 & 0.000082 & 16.3 & 324 \\
\hline 9503 & 34.3 & 127.8 & 961.5 & 139.7 & 0.000082 & 7.6 & 340 \\
\hline 9711 & 34.0 & 127.1 & 985.0 & 107.7 & 0.000081 & 9.9 & 316 \\
\hline 9809 & 34.6 & 127.0 & 980.0 & 59.4 & 0.000083 & 4.4 & 339 \\
\hline 9905 & 34.6 & 126.2 & 988.3 & 22.2 & 0.000083 & 5.1 & 203 \\
\hline 9907 & 34.8 & 125.9 & 975.0 & 44.9 & 0.000083 & 7.2 & 178 \\
\hline 9908 & 33.2 & 126.3 & 994.0 & 171.5 & 0.000080 & 7.8 & 265 \\
\hline 0006 & 34.0 & 128.7 & 988.5 & 233.3 & 0.000081 & 6.4 & 344 \\
\hline 0012 & 35.9 & 124.3 & 965.0 & 216.2 & 0.000085 & 10.9 & 170 \\
\hline 0014 & 34.3 & 128.2 & 970.0 & 171.0 & 0.000082 & 12.6 & 348 \\
\hline 0205 & 35.3 & 125.8 & 980.9 & 72.9 & 0.000084 & 10.4 & 141 \\
\hline 0209 & 33.0 & 125.6 & 986.3 & 205.1 & 0.000079 & 5.8 & 241 \\
\hline 0215 & 34.9 & 127.3 & 964.1 & 85.3 & 0.000083 & 8.3 & 10 \\
\hline 0306 & 33.5 & 128.6 & 975.0 & 250.5 & 0.000080 & 15.9 & 334 \\
\hline 0314 & 33.9 & 127.5 & 947.0 & 138.8 & 0.000081 & 12.3 & 326 \\
\hline 0415 & 33.6 & 128.1 & 970.0 & 205.0 & 0.000081 & 15.4 & 330 \\
\hline 0603 & 34.7 & 126.5 & 981.2 & 9.7 & 0.000083 & 11.8 & 342 \\
\hline 0711 & 34.3 & 127.4 & 969.3 & 105.9 & 0.000082 & 6.7 & 337 \\
\hline 0807 & 36.5 & 124.3 & 998.0 & 268.3 & 0.000087 & 11.2 & 143 \\
\hline 1007 & 35.1 & 124.9 & 973.0 & 136.1 & 0.000084 & 11.4 & 169 \\
\hline 1105 & 34.6 & 124.4 & 980.0 & 178.7 & 0.000083 & 15.5 & 182 \\
\hline 1109 & 34.4 & 123.9 & 975.0 & 229.3 & 0.000082 & 7.3 & 184 \\
\hline 1207 & 34.8 & 126.4 & 993.0 & 1.1 & 0.000083 & 10.8 & 354 \\
\hline 1210 & 32.3 & 125.2 & 971.3 & 285.3 & 0.000078 & 11.9 & 240 \\
\hline 1214 & 34.4 & 127.0 & 987.9 & 66.9 & 0.000082 & 12.8 & 331 \\
\hline 1215 & 34.5 & 125.2 & 960.0 & 115.8 & 0.000082 & 9.4 & 188 \\
\hline 1216 & 34.6 & 128.0 & 962.4 & 145.6 & 0.000083 & 9.3 & 354 \\
\hline 1324 & 33.2 & 128.0 & 973.4 & 226.0 & 0.000080 & 13.4 & 319 \\
\hline 1412 & 35.1 & 125.3 & 990.8 & 99.7 & 0.000084 & 1.6 & 163 \\
\hline
\end{tabular}


여기서 $V_{T}$ 는 태풍 이동속도(translation velocity)(m/s), $\theta$ 는 태 풍 진행 방향을 기준으로 시계방향의 관심지점 사이의 각도 $\left({ }^{\circ}\right)$, $r_{0}$ 는 최대풍속반경(radius to maximum wind; RMW)(km), $\Delta p\left(=p_{\infty}-p_{c}\right)$ 는 기압차(pressure deficit)(hPa), $p_{\infty}$ 와 $p_{c}$ 는 각 각 태풍 영향권 밖의 기압 $(\fallingdotseq 1013 \mathrm{hPa})$ 과 중심기압, $f$ 는 코리 올리 파라메타, $\rho$ 는 공기밀도이다. $B$ 는 태풍 프로파일의 형 상을 결정하는 파라메타로 대략 $1<B<2.5$ 의 범위에 있으며, 식 (2)와 같은 Vickery et al.(2000)이 제안한 식을 이용하여 산 정하였다.

$$
B=1.38+0.00184 \Delta p-0.00309 r_{0}
$$

최대풍속반경 산정식은 Graham and Nunn(1959)이 제시한 식을 비롯하여 Vickery et al.(2000), Powell et al.(2005), Willoughby et al.(2006) 등 다양한 식이 제안되고 있다. 이 러한 식들은 대부분 북대서양에서 발생한 허리케인에 대하여 유도된 식으로 중심기압과 위도 등의 함수로 최대풍속반경이 산정되고 있다. 이외에 국내에서 Kang et al.(2002)이 제안한 식은 다음 식 (3)과 같이 중심기압만의 함수로 제시되고 있 다. 최대풍속반경은 태풍의 공간적 풍속분포를 결정하게 되 므로 태풍 또는 해일 모의시 매우 중요한 매개변수이지만 본 연구의 주관심사가 태풍의 실제적 모의에 있지 않으므로 최 대풍속반경이 얼마인지는 크게 중요하지 않게 된다. 오히려 식 (1)에서 볼 수 있는 바와 같이 태풍중심에서 관심지역 사 이의 거리 $(r)$ 가 최대풍속반경 $\left(r_{0}\right)$ 에 얼마나 근접한지가 훨씬 중 요한 요소이므로 본 연구에서는 국내 환경이 반영된 식 (3) 을 채택하였다.

$$
r_{0}=2606.7\left(1013-p_{c}\right)^{-0.8811}
$$

한편 식 (1)을 사용하여 추정한 풍속은 경고도에서의 값이 고 구조물 설계를 위해서는 해수면 $10 \mathrm{~m}$ 에서의 풍속 $V_{s, 10}$ 으 로 변환해야 한다. 본 연구에서는 Kwon and Lee(2008)가 채 택한 방식과 동일하게 다음 식 (4)(Vickery and Twisdale, $1995)$ 를 사용하였다. 이때 1 분 평균과 10 분 평균 풍속의 비
율은 1.18을 사용(Batts et al., 1980)하였다.

$$
V_{s, 10}=\left\{\begin{array}{cc}
0.825 \cdot V_{g, 1} / 1.18 & r \leq 2 r_{0} \\
V_{g, 1} / 1.18 \cdot\left[0.825-0.0375 \cdot\left(r / r_{0}-2\right)\right] & 2 r_{0}<r<4 r_{0} \\
0.750 \cdot V_{g, 1} / 1.18 & r \geq 4 r_{0}
\end{array}\right.
$$

\section{2 매개변수 산정}

풍속 산정식인 식 (1)의 적용을 위해 태풍 매개변수가 산 정되어야 하는데, 각 매개변수에 적합한 확률분포함수를 설 정한 후 임의로 발생시킨 매개변수 세트가 구성된다. 매개변 수별 확률분포함수는 Kwon and Lee(2008)에 정리되어 있는 유사 연구들을 참고하여 선정하였으며 Table 1을 토대로 매 개변수가 산정된다. 선정된 확률분포함수 및 산정된 매개변 수값과 함께 확률분포함수의 적합도 검정결과를 Table 2에 제 시하였다. Chi-square검정을 비롯한 4 가지 검정결과 $5 \%$ 유의 수준에서 모두 통과하고 있어 모든 매개변수에서 채택한 각 확률분포함수가 적합한 것으로 나타나고 있고 Fig. 2에 도시 된 누가분포함수 역시 검정결과와 일맥상통하고 있음을 보이 고 있다.

이와 같이 산정된 확률변수값을 이용하여 Monte-Carlo 시 뮬레이션을 반복하여 설계풍속을 산정하였다. 시뮬레이션에 의하여 구한 풍속을 크기순으로 정렬하면 $i$ 번째 풍속 $\left(V_{i}\right)$ 에 해 당하는 재현기간 $(N)$ 은 다음 식 (5)와 같이 산정된다(Kim et al., 2005; Kwon and Lee,2008).

$$
N=\frac{1}{1-\exp \left[-n_{\text {rate }}\left(1-\frac{i}{(m+1)}\right)\right]}
$$

여기서 $m$ 은 생성된 풍속의 총 개수이고 $n_{\text {rate }}$ 는 연간 태풍 내 습 횟수이다. Kwon and Lee(2008)에 따르면 적절한 반복횟 수는 50,000회 이상으로 제안되고 있어 본 연구에서는 100,000 회의 시뮬레이션을 시행하였다.

\begin{tabular}{|c|c|c|c|c|c|c|c|}
\hline \multirow[b]{2}{*}{ Parameter } & \multicolumn{3}{|c|}{ Probability distribution fn. } & \multicolumn{4}{|c|}{ Goodness of fit test } \\
\hline & $\begin{array}{l}\text { Vickery } \\
(1995)\end{array}$ & $\begin{array}{l}\text { Kwon and } \\
\text { Lee(2008) }\end{array}$ & Present & $x^{2}$ & $\mathrm{~K}-\mathrm{S}$ & CVM & PPCC \\
\hline Frequency & Uniform & Uniform & Uniform & & & & \\
\hline Frequency & Poisson & Poisson & Poisson & & & & \\
\hline $\begin{array}{c}\text { Pressure } \\
\text { Deficit }\end{array}$ & Weibull & Weibull & Weibull & $5.59(\bigcirc)$ & $0.12(\bigcirc)$ & $0.10(\bigcirc)$ & $0.98(\bigcirc)$ \\
\hline $\begin{array}{c}\text { Translation } \\
\text { Velocity }\end{array}$ & Lognormal & Lognormal & Linear step fn. & $2.29(\bigcirc)$ & $0.10(\bigcirc)$ & $0.07(\bigcirc)$ & $0.98(\bigcirc)$ \\
\hline Distance & Uniform & Uniform & Uniform & $3.00(\bigcirc)$ & $0.10(\bigcirc)$ & $0.08(\bigcirc)$ & $0.98(\bigcirc)$ \\
\hline Angle & - & Linear step fn. & Linear step fn. & $1.84(\bigcirc)$ & $0.08(\bigcirc)$ & $0.04(\bigcirc)$ & $0.98(\bigcirc)$ \\
\hline
\end{tabular}

\section{3 빈도별 풍속}

식 (4)와 식 (5)로부터 재현기간별 최대풍속을 산정할 수 있

Table 2. Probability distribution functions and goodness of fit test of the parameters 

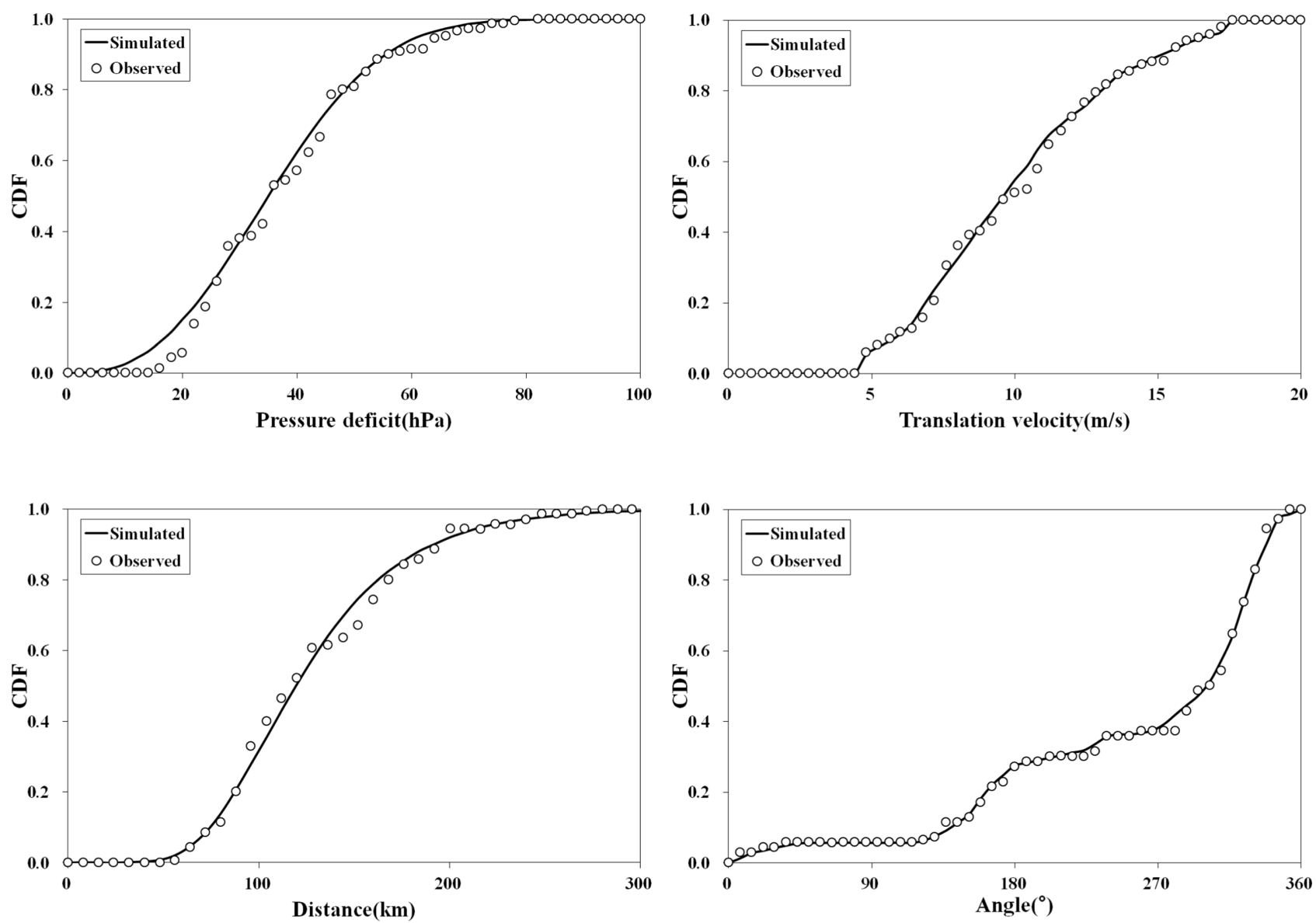

Fig. 2. Comparisons of simulated CDF and observed CDF of the parameters.

Table 3. Estimation of extreme wind $\operatorname{speed}(\mathrm{m} / \mathrm{s})$

\begin{tabular}{ccccccc}
\hline \hline & $\begin{array}{c}\text { Ko et al. } \\
(2014)^{*}\end{array}$ & $\begin{array}{c}\text { Kwon and Lee } \\
(2008)\end{array}$ & $\begin{array}{c}\text { Kim and Ha } \\
(2004)\end{array}$ & & \multicolumn{2}{c}{ Present } \\
\hline Return Period (yr) & & 100 & 27.4 & 50 & 100 & 200 \\
Incheon & - & 22.1 & 23.9 & 25.6 & 27.0 \\
Gunsan & 39.3 & 28.4 & 30.7 & 28.1 & 30.0 & 31.5 \\
Mokpo & 46.7 & 29.8 & 38.9 & 30.1 & 31.9 & 33.3 \\
Jeju & 49.2 & 36.1 & 34.0 & 35.8 & 37.4 \\
\hline
\end{tabular}

*The result of Ko et al.(2014) is the wind speed at $100 \mathrm{~m}$ height

으며 목포와 동일한 방법으로 인천, 군산, 그리고 제주지역까 지 포함한 100년 빈도 풍속을 타연구결과와 함께 Table 3에 제시하였다. 여기서 Ko et al.(2014)의 결과는 목포와 군산 및 제주 등이 외해쪽으로 멀리 이격되어 있는 해상에 위치한 곳 인 동시에 $100 \mathrm{~m}$ 상공에서의 값으로 제시되어 있어 본 연구 결과에 비해 상당히 크게 산정되는 것으로 파악되고 있다. 다 른 두 연구결과와 비교해 보면 본 연구결과가 중간 정도의 값 을 보이고 있어 전반적으로 잘 일치하고 있다고 평가된다. 특 히 $\mathrm{Kim}$ and $\mathrm{Ha}(2004)$ 를 제외하고 제주-목포-군산-인천 순 (Fig. 1의 위치 참조)으로 풍속이 작게 산정되고 있음을 볼 수 있는데, 북쪽에 위치할수록 풍속이 약해지는 것으로 나타나는 것은 Table 1에 제시된 대상태풍의 최근접시 중심기압이 북쪽
으로 갈수록 약화되는 것과 일맥상통한 결과로 해석된다. 이 러한 경향은 함께 제시한 50년 빈도 및 200년 빈도 결과에 서도 확인할 수 있다.

\section{4 민감도 분석}

각 매개변수가 풍속에 미치는 영향성 분석을 위하여 목포지 역의 매개변수에 따른 풍속의 분포를 Fig. 3 에 도시하였다. Fig. 3(a)의 기압강하량이 커질수록 풍속이 크게 산정되는 경 향을 보이고 있으며, Fig. 3(b)의 최근접거리 $(r)$ 는 최대풍속반 경 $\left(r_{0}\right)$ 이 위치한 지점 부근에서 빠른 풍속을 보이고 있는데 Fig. 1의 위치각에 따라 위험반원과 가항반원으로 구분되어 음(-)의 값으로 표시된 위험반원에서 더욱 큰 풍속을 보이고 


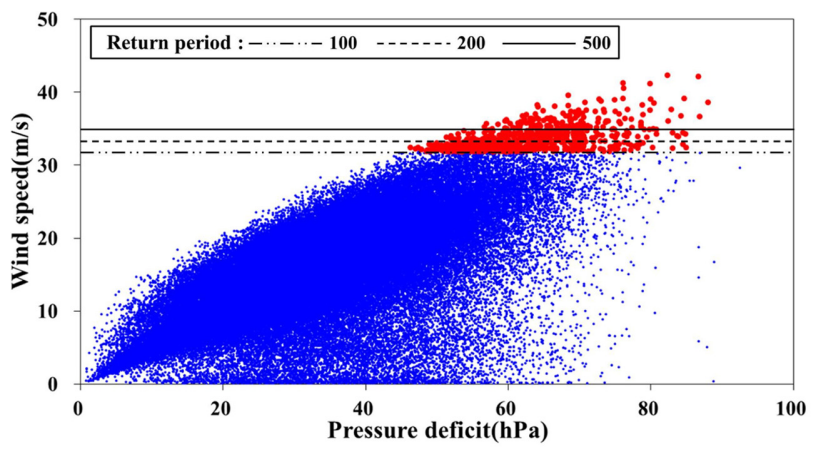

(a) Pressure deficit

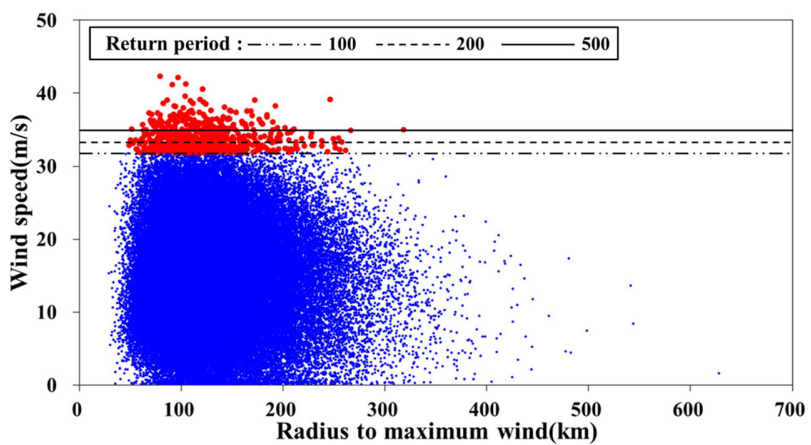

(c) Radius to maximum wind

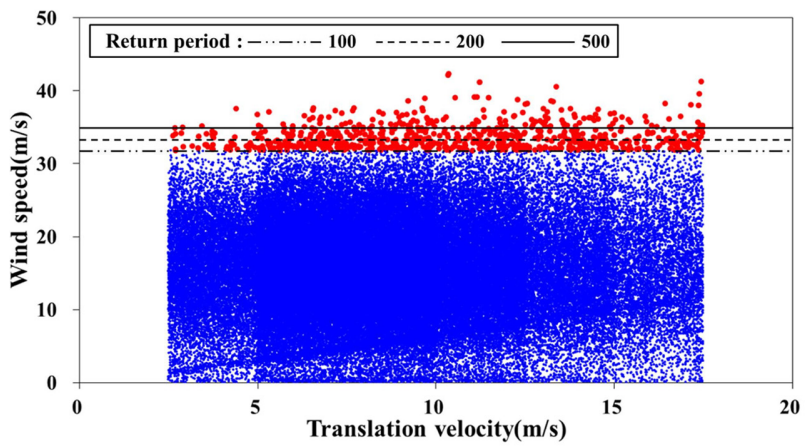

(e) Translation velocity

Fig. 3. Dot plot result regarding to parameter sensitivity.

있다. 식 (3)에 제시된 최대풍속반경에 의한 결과는 Fig. 3(c) 와 같은데, 최대풍속반경 자체보다 Fig. 3(d)에 보인 바와 같 이 태풍중심과의 거리 $(r)$ 와 최대풍속반경 $\left(r_{0}\right)$ 과의 차이에 의한 풍속 영향성이 더욱 크게 나타나고 있다. Fig. 3(e)의 이동속 도의 경우 식 (1)에 보인 바와 같이 이동속도가 빠를수록 최 대풍속은 크게 나타나는 경향이 미미하게 나타나고 있다. Fig. $3(\mathrm{f})$ 의 위치각에 의한 풍속 영향성은 $270^{\circ}$ 를 전후로 설정되는 가항반원 및 위험반원 구분에 따른 영향은 크게 나타나고 있 지만, 많은 모의가 이루어지는 구간에서 그에 비례하여 큰 풍 속값이 많이 발생함을 감안하면 동일 반원에서 풍속 영향성 은 크지 않은 것으로 평가된다.

표준태풍을 설정하기 위해서는 민감한 매개변수 순으로 먼 저 결정되어야 하므로 매개변수별로 풍속에 미치는 상대적 영 향성을 정량화하여야 하는데 대표적인 방법으로 매개변수 변 화에 따른 풍속변화에 대한 상관계수를 산정하는 방법이 있 다. Fig. 3(a)에 보인 기압강하량의 경우 상관계수가 0.64로 풍속과의 상관성이 선형적으로 뚜렷하게 보이고 있는 반면 여

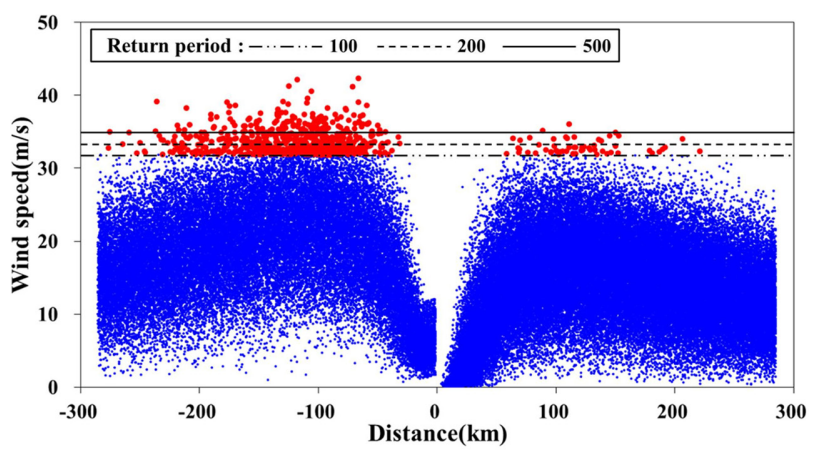

(b) Distance

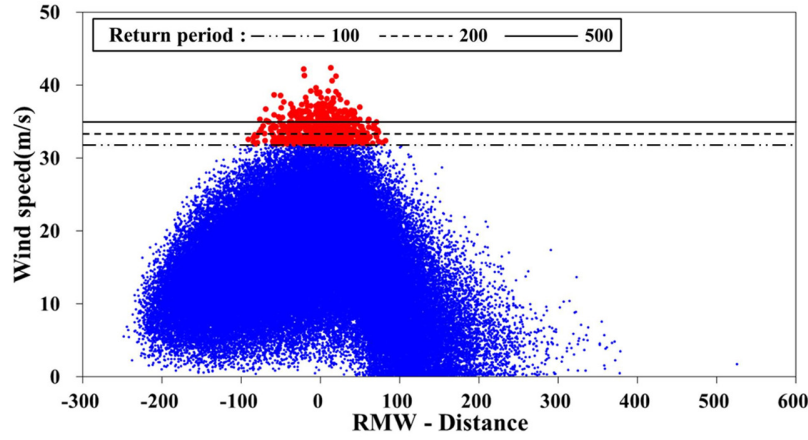

(d) RMW - Distance

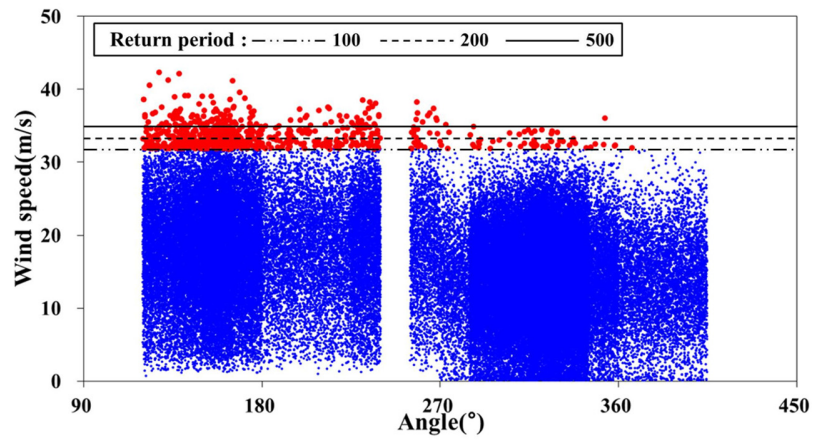

(f) Angle

타 매개변수에서는 상관성이 옅거나 비선형적 상관성을 보이 고 있다. 특히 Fig. 3(b)의 최근접거리는 Fig. 1의 위치각에 따라 위험반원과 가항반원으로 구분된 상태에서 풍속과의 비 선형 상관성이 분명해 보이지만 상관계수로 정량화시키기에 는 한계가 있다.

또 다른 방법으로 기준 매개변수 세트를 설정한 후 매개변 수 변화에 따른 풍속의 변화를 정량적으로 산정하는 방법이 있다. 즉, 매개변수별 평균치를 기준매개변수 세트로 구성하 여 풍속을 구한 후 평균치로부터 표준편차만큼 증감시킨 매 개변수 값에 의한 풍속과의 비를 산정함으로써 민감도를 정 량화할 수 있다. 정량화된 민감도분석 결과를 각 매개변수의 기준치인 평균과 표준편차, 그리고 기준 매개변수에 따른 풍 속과 함께 Table 4에 제시하였다. 기압강하량의 민감도 비율 이 1.25 및 0.71 로 단연 민감한 매개변수로 나타나고 있음을 볼 수 있는 반면 최대풍반경과 최근접거리의 경우 기준 매개 변수에서 표준편차만큼 증감된 경우 민감도 비율이 모두 1 보 다 작은 값을 보이고 있어 매개변수 변화에 따른 민감도를 정 
Table 4. Sensitivity analysis

\begin{tabular}{|c|c|c|c|c|c|}
\hline \multicolumn{3}{|c|}{ Typhoon parameter } & \multicolumn{3}{|c|}{$\begin{array}{l}\text { Wind speed (m/s) } \\
\text { (Ratio) }\end{array}$} \\
\hline & $\operatorname{mean}(\mu)$ & st.d. $(\sigma)$ & $\mu$ & $\mu+\sigma$ & $\mu-\sigma$ \\
\hline RMW (km) & 130.9 & 47.2 & $\begin{array}{l}27.0 \\
(1.0)\end{array}$ & $\begin{array}{c}26.8 \\
(0.99)\end{array}$ & $\begin{array}{c}25.2 \\
(0.93)\end{array}$ \\
\hline Distance (km) & 146.8 & 80 & $\begin{array}{l}27.0 \\
(1.0)\end{array}$ & $\begin{array}{c}22.8 \\
(0.84)\end{array}$ & $\begin{array}{c}25.9 \\
(0.96)\end{array}$ \\
\hline $\begin{array}{c}\text { Translation } \\
\text { velocity }(\mathrm{m} / \mathrm{s})\end{array}$ & 8.8 & 3.5 & $\begin{array}{l}27.0 \\
(1.0)\end{array}$ & $\begin{array}{c}28.5 \\
(1.06)\end{array}$ & $\begin{array}{r}25.7 \\
(0.95)\end{array}$ \\
\hline Pressure deficit $(\mathrm{hPa})$ & 34.3 & 13.4 & $\begin{array}{l}27.0 \\
(1.0)\end{array}$ & $\begin{array}{c}33.7 \\
(1.25)\end{array}$ & $\begin{array}{c}19.3 \\
(0.71)\end{array}$ \\
\hline
\end{tabular}

Table 5. Concentration coefficients

\begin{tabular}{cccccccc}
\hline \hline & & Pressure deficit & Distance & RMW & RMW - Distance & Tran. velocity & Angle \\
\hline \multirow{2}{*}{ variance } & $\sigma_{t}^{2}$ & 178.1 & 6372.4 & 2230.7 & 8488.4 & 12.0 & 8628.7 \\
& $\sigma^{2}$ & 62.6 & 1970.7 & 1558.4 & 968.9 & 14.1 & 2825.7 \\
\multirow{2}{*}{$C$} & 0.35 & 0.31 & 0.70 & 0.11 & 1.17 & 0.33 \\
\hline
\end{tabular}

량화시키기에는 한계가 있음을 시사하고 있다.

따라서 본 연구에서는 Fig. 3의 각 매개변수별로 해당 매 개변수가 풍속 크기에 민감한지 여부를 다음 식 (6)을 통해 정량적으로 비교 평가하였다. 즉, 식 (6)과 같이 분산의 비로 정의되는 집중도 $(C)$ 라 명명한 값이 작을수록 해당 매개변수 가 한정된 좁은 범위에서 큰 풍속을 유발하는 반면 1 에 가 까울수록 고빈도 풍속이 해당 매개변수에 둔감한 것으로 평 가된다.

$$
C=\sigma^{2} / \sigma_{t}^{2}
$$

여기서 $\sigma^{2}$ 은 한계풍속 이상에 해당하는 자료의 횡방향 분산 이고 $\sigma_{t}^{2}$ 은 전체자료의 횡방향 분산이다.

집중도를 산정하기 위한 한계풍속으로 Fig.3에 보인 바와 같이 100 년 빈도 풍속을 적용하여 100 년 빈도 이상의 풍속 자료는 진하게 나타내었다. 산정된 집중도를 Table 5에 제시 하였는데, 최근접거리(0.31) 및 최대풍반경 $(0.70)$ 자체보다 그 차이값(0.11)이 가장 민감한 것으로 나타나고 있다. 위치각 (0.33)은 위험반원과 가항반원의 구분에 기인하여 민감한 편 으로 나타나고 있으며 기압강하량 $(0.35)$ 역시 민감하게 나타 나고 있다. 이동속도(1.17)는 둔감한 매개변수로 나타나고 있 지만 이 값이 커질수록 최대풍속이 크게 나타나는 경향이 미 약하게 보이고 있다.

\section{4. 표준태풍}

\section{1 매개변수 설정}

본 연구에서 추구하는 목표는 임의의 지역에서 특정 재현 기간별 풍속 산정과 함께 해당 풍속을 발생시키는 평균적인
태풍을 설정하는 것이다. 이를 표준태풍이라 명명하였고 설정 된 태풍에 대하여 해일모의를 통해 빈도별 해일고까지 산정 할 수 있으며, 더 나아가 EST기법에 가상태풍으로 반영할 수 있게 된다. 이를 위해 우선 200년 빈도의 표준태풍에 대한 매 개변수를 다음과 같이 민감한 매개변수 순으로 설정하였다.

Table 5에 보인 바와 같이 최근접거리와 최대풍반경의 차 이가 가장 민감하며 위치각과 중심기압차 순으로 민감한 매 개변수로 나타나고 있는 반면 이동속도는 둔감한 것으로 나 타나고 있다. 따라서 최근접거리와 최대풍반경의 관계를 먼 저 설정한 후 여타 매개변수를 순차적으로 설정하여 표준태 풍을 생성하고자 한다. 전술하였듯이 최근접거리는 최대풍반 경에 근접할수록 풍속이 증가함은 자명한 사실이다. 본 연구 의 목적이 예보에 있지 않으므로 우선 최근접거리가 최대풍 반경과 일치할 경우를 표준태풍의 첫 번째 조건으로 선택하 였다. 이때 위치각의 민감도를 반영하여 최근접거리는 위치 각이 90도 270도 사이에 있는 위험반원에 해당하면서 최대 풍반경과 일치하도록 선정한다. 10만번 모의된 태풍사상 중 200 년 빈도 풍속에 근사 $(32.8 \sim 33.8 \mathrm{~m} / \mathrm{sec})$ 하면서 위험반원에 해당하는 동시에 최근접거리와 최대풍반경과의 비율이 $0.9 \sim 1.1$ 범위에 해당하는 경우는 총 58 번 발생하였으며 이들이 표준 태풍의 압축된 후보군으로 선별된다. 이들로부터 민감도분석 결과를 감안하여 기압강하량과 이동속도를 산정하여야 하는 데 58개 사상별 기압강하량과 이동속도를 Fig. 4에 제시하였 다. 기압강하량의 경우 $50 \sim 80 \mathrm{hPa}$ 사이에 집중적으로 분포하 고 있으며 이동속도의 경우 전체 범위에 산재하고 있으며 양 매개변수는 미약하게 반비례하는 경향을 보이고 있다. 따라 서 평균적인 200년 빈도 표준태풍은 Fig. 4에 나타낸 ( )로 표시된 중앙부에 위치하는 매개변수 세트를 선택함으로써 Table 6과 같이 설정하였다. 목포(MP) 외에 인천(IC), 군산 
(GS), 제주(JJ), 이어도(IED) 역시 동일한 방법으로 설정할 수 있으며 200년 빈도 결과를 100 년 빈도 결과와 함께 Table 6 에 제시하였다.

\section{2 경로 및 기압강하량 설정}

목포 지역에 해당하는 표준태풍 제원은 Table 6에 제시된 바와 같이 설정될 수 있는데, 이는 태풍경로상에서 목포에 최 근접하는 1 개 지점의 정보에 불과하므로 태풍에 의한 해일의 수치모의 등에 활용하기 위해서는 태풍경로상의 추가적인 조 건이 요구된다. Table 6에 제시된 바와 같이 목포 뿐 아니라 인천, 군산, 제주 등지에서 태풍이 최근접하는 상황에 대한 정 보, 즉 최대풍속, 최대풍반경, 기압강하량, 이동속도 등의 매 개변수를 추가적으로 설정하였다. 이러한 정보를 태풍진행 방 향으로 순차적으로 설정함으로써 표준태풍을 완성할 수 있는 데, 제주 이남에서의 기압강하량을 산정하기 위하여 국내 최 남단인 이어도에서의 분석을 추가하여 동일 위도의 표준태풍 에 반영하였다. 이렇게 설정된 서해안을 통과하는 200년 빈 도 표준태풍의 경로와 기압변화상을 Fig. 5에 도시하였다. 제시된 결과에 따르면 인천, 군산, 목포 등 서해안 주요도

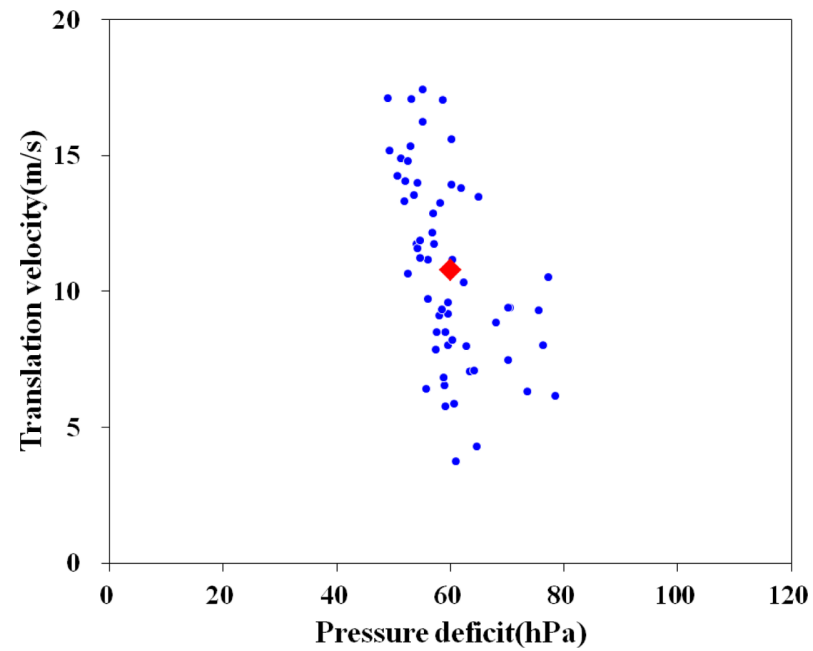

Fig. 4. Pressure deficit vs translation velocity.
시에 대한 해석으로부터 설정된 표준태풍의 경로는 Fig. 5에 보인 바와 같이 태풍 Bolaven(1215)의 경로와 매우 유사하게 나타나고 있음을 보여주고 있다. 태풍 Bolaven(1215)에 비해 중심기압이 낮게 형성되고 있으며 북쪽에 위치한 지점일수록 태풍의 세력이 약화되어 Table 6에 제시된 바와 같이 기압강 하량과 최대풍속이 감소하는 반면 최대풍반경은 증가하고 있 음을 보이고 있다.

이러한 표준태풍에 대하여 해일모의를 수행함으로써 표준 태풍으로 야기되는 빈도별 해일고 역시 산출할 수 있으며 이 는 해당빈도 풍속과 일맥상통하는 의미를 갖게 된다. 더 나 아가 극치해면고 산정과 관련된 $\mathrm{EST}$ 기법에 있어 가상태풍의 빈도설정에도 활용될 수 있다.

\section{3 가항반원}

4.1절에 기술한 바와 같이 Fig. 3(b)의 왼쪽인 음(-)의 최근 접거리인 경우는 태풍중심의 위치가 해당지점(목포)의 서측

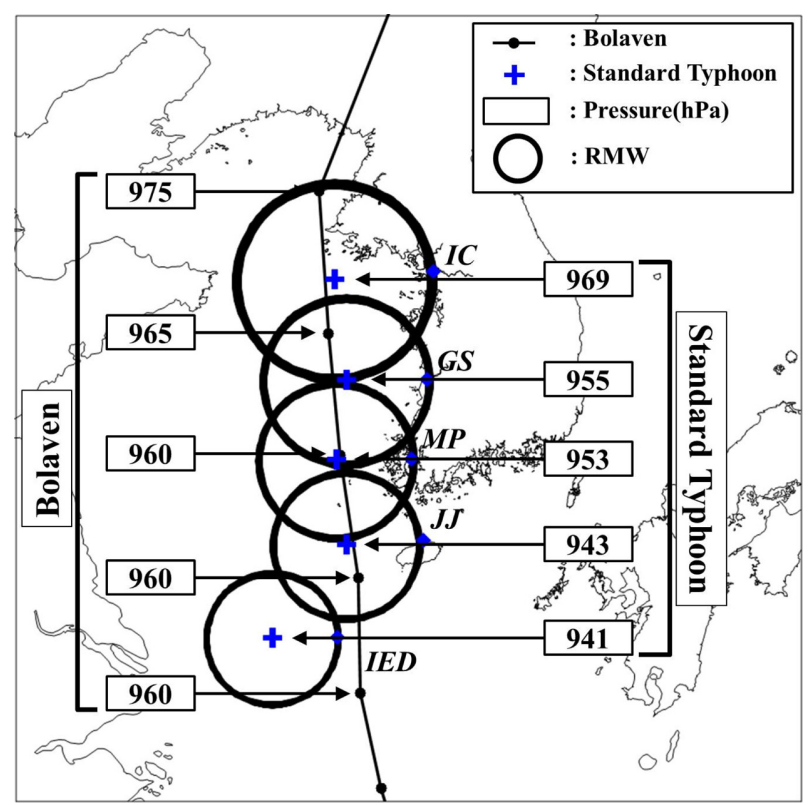

Fig. 5. Pressure variation of real Bolaven and the standard typhoon.

Table 6. Specification of the standard typhoons

\begin{tabular}{|c|c|c|c|c|c|}
\hline Return Period & Site & Max. wind speed $(\mathrm{m} / \mathrm{s})$ & RMW (km) (=Distance) & Pressure deficit $(\mathrm{hPa})$ & Translation velocity $(\mathrm{m} / \mathrm{s})$ \\
\hline \multirow{5}{*}{$100 \mathrm{yr}$} & IC & 25.6 & 154 & 40 & 12.8 \\
\hline & GS & 30.0 & 142 & 53 & 10.4 \\
\hline & MP & 31.9 & 134 & 58 & 10.4 \\
\hline & $\mathrm{JJ}$ & 35.8 & 110 & 68 & 9.9 \\
\hline & IED & 35.6 & 119 & 71 & 7.4 \\
\hline \multirow{5}{*}{$200 \mathrm{yr}$} & IC & 27.0 & 152 & 44 & 12.3 \\
\hline & GS & 31.5 & 147 & 58 & 10.0 \\
\hline & MP & 33.3 & 124 & 60 & 10.8 \\
\hline & $\mathrm{JJ}$ & 37.4 & 118 & 70 & 10.3 \\
\hline & IED & 37.0 & 108 & 72 & 8.0 \\
\hline
\end{tabular}


으로서 해당지점에서의 진행속도와 풍속이 동일 방향인 위험 반원인 경우이다. 반면 그림의 우측인 양 $(+)$ 의 최근접거리인 경우는 태풍중심이 동측으로서 가항반원에 해당하는 경우이 다. Fig. 1 에 보인 바와 같이 목포의 경우 가항반원을 통과 하는 태풍이 2 배 가까이 많지만 위험반원의 최고풍속이 더욱 크게 산정되고 있음을 볼 수 있다. 한편 $\operatorname{Kang}(2015)$ 이 지적 했듯이 서해안 지점에서는 동측으로 통과하는 남해안 상륙 태 풍의 경우 set-down에 의한 음의 해일고가 발생할 수 있다. 따라서 동측으로 통과하는 태풍만을 대상으로 동일한 해석을 통해 저극조위 산정의 기초로서 음의 해일고가 유발되는 최 대풍속 산정 역시 가능하다.

즉, Fig. 1과 Table 1에서 최근접 위치의 방향이 90 270도 인 태풍 19개를 제외한 상태에서 동일한 방법으로 몬테칼로 해석을 시행한 결과 Table 7과 같이 4개 지점에서 빈도별 풍 속이 산정되었다. 또한 앞에서와 동일한 방법으로 빈도별 표 준태풍에 해당하는 매개변수 역시 산정하였으며 Table 8에 제 시하였다. 이러한 표준태풍을 이용하여 해일모의를 수행하게 되면 해당 재현기간의 음(-) 해일고를 산정할 수 있게 되고 더 나아가 조위자료와 연동된 EST 기법에 의해 저극조위 역 시 산정이 가능하다.

\section{5. 결론 및 제언}

몬테칼로 시뮬레이션을 이용하여 서해안 4개 지점에서 빈

Table 7. Estimation of extreme wind speed (in case of navigable semicircle $)(\mathrm{m} / \mathrm{s})$

\begin{tabular}{ccc}
\hline & \multicolumn{2}{c}{ Return Period(yr) } \\
\cline { 2 - 3 } & 100 & 200 \\
\hline Incheon & 20.9 & 22.4 \\
Gunsan & 25.8 & 27.3 \\
Mokpo & 28.2 & 29.7 \\
Jeju & 33.0 & 34.6 \\
\hline
\end{tabular}

도별 풍속을 산정한 결과 Kwon and Lee(2008) 등 타연구와 유사한 결과를 도출하였다. 또한 풍속에 미치는 상대적인 영 향성을 파악하기 위하여 Holland(1980) 모델의 매개변수별 민 감도 역시 분석하였다. 최근접거리가 최대풍반경에 얼마나 가 까운지가 최대풍속 산정에 가장 민감한 매개변수임을 보이고 있고 기압강하량 역시 매우 민감한 것으로 나타나고 있는 반 면 이동속도와 위치각은 둔감한 결과를 보이고 있다. 특히 위 치각은 위험반원과 가항반원으로 구분된 상태에서 동일 반원 에서는 최대풍속에 미치는 영향이 크지 않았다.

이를 토대로 빈도별 풍속을 야기하는 평균적인 태풍상황 을 의미하는 표준태풍을 생성할 수 있었다. 즉, 위험반원에 해당하고 최근접거리가 최대풍반경에 근접한 상태의 빈도 별 최대풍속을 초래하는 매개변수 세트 중에서 기압강하량 과 이동속도의 평균값을 선정함으로써 특정지점에서 최근 접한 상태의 표준태풍을 설정할 수 있다. 서해안에 연한 인 천, 군산, 목포, 제주 등지에서 각각 이러한 해석을 동일하 게 수행함으로써 표준태풍의 경로와 기압변화상 등을 확정 지을 수 있다.

이렇게 만들어진 표준태풍을 태풍-해일 모의가 가능한 해 수유동 수치모형에 적용하게 되면 풍속의 빈도와 일맥상통 하는 해일고를 산정할 수 있게 되며 이는 EST 방법의 트레 이닝세트의 가상태풍 설정에 활용될 수 있을 뿐 아니라 극 치해면고 산정을 위한 설계태풍으로도 활용될 수 있다. 또 한 가항반원에 해당하는 자료만을 대상으로 해석하게 되면 서해안 지역에서 음의 해일고를 유발하는 빈도별 최대풍속 을 산정할 수 있으며, 해당 빈도의 표준태풍 역시 생성할 수 있다.

그러나 본 연구에서 채택한 방법 역시 1978년부터 30여년 자료로부터 산정된 결과이므로 고빈도 예측값을 산정하기에 는 자료의 비정상성과 불확실성에 대한 담보는 부족한 상황 이며, 특히 지구온난화 등에 기인한 미래 태풍의 강도변화는 간과되고 있는 실정이어서 기후변화 등에 따른 영향성이 보 완되어야 하며 이는 추후 연구과제로 남겨둔다.

Table 8. Specification of the standard typhoons (in case of navigable semicircle)

\begin{tabular}{|c|c|c|c|c|c|}
\hline Return Period & Site & Max. wind speed $(\mathrm{m} / \mathrm{s})$ & $\begin{array}{l}\text { RMW (km) } \\
\text { (=Distance) }\end{array}$ & Pressure deficit $(\mathrm{hPa})$ & $\begin{array}{c}\text { Translation velocity } \\
(\mathrm{m} / \mathrm{s})\end{array}$ \\
\hline \multirow{5}{*}{$100 \mathrm{yr}$} & $\mathrm{IC}$ & 20.9 & 166.4 & 42 & 9.9 \\
\hline & GS & 25.8 & 135.1 & 55 & 8.6 \\
\hline & MP & 28.2 & 132.0 & 62 & 8.4 \\
\hline & $\mathrm{JJ}$ & 33.0 & 105.6 & 73 & 7.4 \\
\hline & IED & 33.8 & 111.6 & 75 & 6.9 \\
\hline \multirow{5}{*}{$200 \mathrm{yr}$} & IC & 22.4 & 158.5 & 45 & 10.5 \\
\hline & GS & 27.3 & 137.9 & 60 & 8.6 \\
\hline & MP & 29.7 & 127.5 & 65 & 7.7 \\
\hline & $\mathrm{JJ}$ & 34.6 & 101.3 & 78 & 8.5 \\
\hline & IED & 35.4 & 92.3 & 79 & 7.4 \\
\hline
\end{tabular}




\section{감사의 글}

본 연구는 미래창조과학부 원자력연구개발사업의 ‘극한외부 사건 리스크 평가기술 개발' 사업 위탁과제 연구임(국내원전 부지에 대한 태풍 및 태풍해일 시뮬레이션 기술 개발). 또한 이 논문은 2014년 해양수산부의 재원으로 한국해양과학기술 진흥원의 지원을 받아 수행된 연구임(종합해양과학기지 구축 및 활용연구).

\section{References}

Batts, M.E., Russell, L.R. and Simiu, E. (1980). Hurricane wind speeds in the U.S., Journal of Structural Engineering, ASCE, 106(10).

Cho, K.H. and Kim, S.C. (2009). A study on optimal radius of typhoon selection for Monte Carlos method, Proceedings of the Wind Engineering Institute of Korea, Seoul National Univ., 3943.

Divoky, D. and Resio, D.T. (2007). Performance of the JPM and EST methods in storm surge studies. 10th International Workshop on Wave Hindcasting and Forecasting, and Coastal Hazard Symposium, North Shore, Oahu, Hawaii.

Goring, D.G., Stephens, S.A., Bell, R.G. and Pearson, C.P. (2011). Estimation of extreme sea levels in a tide-dominated environment using short data records. Journal of Waterway, Port, Coastal, and Ocean Engineering, 137(3), 150-159.

Holland, G.K. (1980). An analytic model of the wind and pressure profiles in hurricanes, Monthly Weather Review, 108.

Kang, J.W. (2015). Typhoon-surge characteristics in relation with the tide-surge interaction, Journal of Korean Society of Coastal and Ocean Eng., 27(1), 25-37. (in Korean)

Kang, J.W., Kim, Y.S., Cho, H.Y. and Shim, J.-S. (2012). Estimation of extreme sea levels at tide-dominated coastal zone, Journal of Korean Society of Coastal and Ocean Eng., 24(6), 185193. (in Korean)

Kang, S.-W., Jun, K.-C., Bang, G.-H. and Park, K.-S. (2002). Empirical relationship between central pressure and maximum sustained wind for tropical cyclones in Northeast Asian Sea, Asia-Pacific Journal of Atmospheric Science, 38(5), 523-530.

Kim, D.-W., and Ha, Y.-C. (2004). Estimation of wind speeds for return period in the major cities reflecting the recent meteorological data, Journal of the Wind Engineering Institute of Korea, $8(2), 147-154$.
Kim, S.-C., Kim, Y.S. and Yang, Y.-T. (2005). Assessment of severe local storm risks in Ulsan area using Monte Carlos typhoon simulation method and CFD model, Journal of the Wind Engineering Institute of Korea, 9(1), 45-54.

Ko, D.H., Jeong, S.T., Cho, H. and Kang, K.S. (2014). Extreme offshore wind estimation using typhoon simulation, Journal of Korean Society of Coastal and Ocean Eng., 26(1), 16-24. (in Korean)

Kwon, S.-D. and Lee, J.-H. (2008). Estimation of extreme wind speeds in Southern and Western Coasts by typhoon simulation, Journal of Korean Society of Civil Eng., 28(4A), 431-438. (in Korean)

Lee, Y.K., Lee, S.S. and Kim, H.S. (2007). Expectation of extreme wind speed due to typhoon, Proceedings of the Wind Engineering Institute of Korea, Pukyoung National Univ., 1-7.

Powell, M., Soukup, G., Cocke, S., Gulati, S., Morisseau-L., N., Hamid, S., Dorst, N. and Axe, L. (2005). State of Florida hurricane loss projection model: Atmospheric science component, Journal of Wind Eng., 93, 651-674.

Russell, L.R. (1971). Probability distributions for hurricane effects, Journal of Waterways, Harbors and Coastal Engineering, ASCE, 97(1).

Scheffner, N.W., Clausner, J.E., Militello, A., Borgman, L.E., Edge, B.L. and Grace, P.J. (1999). Use and application of the empirical simulation technique; User's guide. US Army Corps of Engineers.

Toro, G.R., Resio, D.T., Divoky, D., Niedoroda, A.W. and Reed, C. (2010). Efficient joint-probability methods for hurricane surge frequency analysis. Ocean Engineering, 37, 125-134.

Vickery P.J., and Twisdale, L.A. (1995). Wind field and filling models for hurricane wind-speed predictions, Journal of Structural Engineering, ASCE, 121(11).

Vickery P.J., Skerlj, P.F. and Twisdale, L.A. (2000). Simulation of hurricane risk in the U.S. using empirical track model, Journal of Structural Engineering, 67, 152-163.

Willoughby, H.E., Darling, R.W.R. and Rahn, M.E. (2006). Parametric representation of the primary hurricane vortex. Part II: A new family of sectionally continuous profiles, Monthly Weather Review, 134, 1102-1120.

Received 27 October, 2015

Revised 26 January, 2016

Accepted 14 February, 2016 